\title{
IMPACT 2002+: A New Life Cycle Impact Assessment Methodology
}

\author{
Olivier Jolliet*, Manuele Margni, Raphaël Charles, Sébastien Humbert, Jérôme Payet, Gerald Rebitzer and \\ Ralph Rosenbaum
}

Industrial Ecology \& Life Cycle Systems Group, GECOS, Swiss Federal Institute of Technology Lausanne (EPFL), CH-1015 Lausanne, Switzerland

*Corresponding author (Olivier.Jolliet@epfl.ch)

\begin{abstract}
The new IMPACT 2002+ life cycle impact assessment methodology proposes a feasible implementation of a combined midpoint/ damage approach, linking all types of life cycle inventory results (elementary flows and other interventions) via 14 midpoint categories to four damage categories. For IMPACT 2002+, new concepts and methods have been developed, especially for the comparative assessment of human toxicity and ecotoxicity. Human Damage Factors are calculated for carcinogens and non-carcinogens, employing intake fractions, best estimates of dose-response slope factors, as well as severities. The transfer of contaminants into the human food is no more based on consumption surveys, but accounts for agricultural and livestock production levels. Indoor and outdoor air emissions can be compared and the intermittent character of rainfall is considered. Both human toxicity and ecotoxicity effect factors are based on mean responses rather than on conservative assumptions. Other midpoint categories are adapted from existing characterizing methods (Eco-indicator 99 and CML 2002). All midpoint scores are expressed in units of a reference substance and related to the four damage categories human health, ecosystem quality, climate change, and resources. Normalization can be performed either at midpoint or at damage level. The IMPACT $2002+$ method presently provides characterization factors for almost 1500 different LCI-results, which can be downloaded at http://www.epfl.ch/impact
\end{abstract}

Keywords: Ecotoxicity; human toxicity; IMPACT 2002+; life cycle impact assessment (LCIA); midpoint/damage approach

\section{Introduction}

Life cycle impact assessment (LCIA) methods aim to connect, as far as possible, and desired, each life cycle inventory (LCI) result (elementary flow or other intervention) to the corresponding environmental impacts. According to ISO 14042, LCI results are classified into impact categories, each with a category indicator. The category indicator can be located at any point between the LCI results and the category endpoints (where the environmental effect occurs) in the cause-effect chain. Within this framework, two main schools of methods have developed:

a) Classical impact assessment methods [e.g. CML (Guinée et al. 2002) and EDIP (Hauschild and Wenzel 1998)] which restrict quantitative modeling to relatively early stages in the cause-effect chain to limit uncertainties and group LCI results in so-called midpoint categories, according to themes. Themes are common mechanisms (e.g. climate change) or commonly accepted grouping (e.g. ecotoxicity).

b) Damage oriented methods such as Eco-indicator 99 (Goedkoop and Spriensma 2000) or EPS (Steen 1999), which try to model the cause-effect chain up to the endpoint, or damage, sometimes with high uncertainties.

Recently, the definition study of the SETAC/UNEP Life Cycle Initiative suggested utilizing the advantages of both approaches by grouping similar category endpoints into a structured set of damage categories. In addition, the concept also works with midpoint categories, each midpoint category relating to one or several damage categories.

As shown in Fig. 1, LCI results with similar impact pathways (e.g. all elementary flows influencing stratospheric ozone concentrations) are grouped into impact categories at midpoint level, also called midpoint categories. A midpoint indicator characterizes the elementary flows and other environmental interventions that contribute to the same impact. The term 'midpoint' expresses the fact that this point is located somewhere on an intermediate position between the

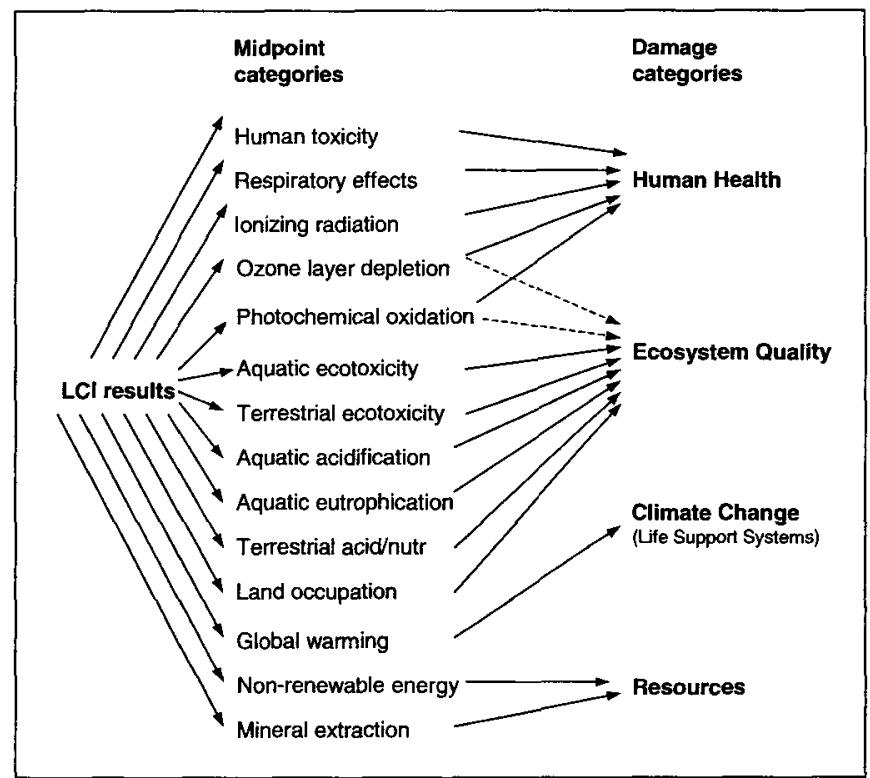

Fig. 1: Overall scheme of the IMPACT 2002+ framework, linking LCI results via the midpoint categories to damage categories, based on Jolliet et al. (2003a) 
LCI results and the damage (or endpoint) on the impact pathway. In consequence, a further step may allocate these midpoint categories to one or more damage categories, the latter representing quality changes of the environment. A damage indicator result is the quantified representation of this quality change. In practice, a damage indicator result is always a simplified model of a very complex reality, giving only a coarse approximation to the quality status of the item. More information on the general concept of such a methodological LCIA framework can be found in Jolliet et al. (2003a).

The new IMPACT 2002+ LCIA methodology proposes a feasible implementation of the aforementioned combined midpoint/damage-oriented approach. Fig. 1 shows the overall scheme of the IMPACT 2002+ framework, linking all types of LCI results via 14 midpoint categories (human toxicity, respiratory effects, ionizing radiation, ozone layer depletion, photochemical oxidation, aquatic ecotoxicity, terrestrial ecotoxicity, terrestrial acidification/nutrification, aquatic acidification, aquatic eutrophication, land occupation, global warming, non-renewable energy, mineral extraction) to four damage categories (human health, ecosystem quality, climate change, resources). An arrow symbolizes that a relevant impact pathway is known or assumed to exist. Uncertain impact pathways between midpoint and damage levels that are not modeled quantitatively are represented by dotted arrows.

In addition to this combined midpoint/damage structure, several scientific challenges had to be tackled, especially in the areas of human toxicological and ecotoxicological impacts:

- How to adapt conventional regulatory-orientated risk assessment methods, often based on conservative assumptions, in order to estimate cumulative chronic toxicological risks and potential impacts in comparative applications such as LCA?
- How to account in a generic but accurate way for non linear functions, such as the intermittent character of rainfall or the differences between indoor and outdoor emissions, which can generate large errors if neglected?

- How to structure fate, exposure, and effect of chemicals in a consistent way following impact pathways, looking at production-based rather than subsistence-based exposures?

To address these challenges new concepts and methods for the comparative assessment of human toxicity and ecotoxicity were developed for the IMPACT 2002+ methodology. For other categories, methods have been transferred or adapted mainly from the Eco-indicator 99 (Goedkoop and Spriensma 2000) and the CML 2002 (Guinée et al. 2002) methods. The following Sections of this paper discuss the main assessment characteristics for midpoint and damage categories, as well as related normalization factors, with a focus on innovative features and performed adaptations.

\section{IMPACT 2002+ at Midpoint Category Level}

Midpoint characterization factors are based on equivalency principles, i.e. midpoint characterization scores are expressed in kg-equivalents of a substance compared to a reference substance. Table 1 shows the reference substances and damage units used in IMPACT 2002+. The principal scope is common to all impact categories: overall long-term effects are being considered through the use of infinite time horizons (sometimes approximated by a 500 years horizon). In general, the average impact has been modeled, avoiding the use of conservative assumptions in determining effect factors. The updated midpoint characterization factors for the number of substances indicated in Table 1 can be downloaded from the Internet at http://www.epfl.ch/impact.

Table 1: Number of LCI results covered, main sources for characterization factors, reference substances, and damage units used in IMPACT 2002+. Sources are: [a] IMPACT 2002 (Pennington et al. 2003a, 2003b), [b] Eco-indicator 99 (Goedkoop and Spriensma 2000), [c] CML 2002 (Guinée et al. 2002), and [d] ecoinvent (Frischknecht et al. 2003)

\begin{tabular}{|c|c|c|c|c|}
\hline $\begin{array}{l}\text { No. of LCl } \\
\text { results covered } \\
\text { [source] }\end{array}$ & Midpoint category & Midpoint reference substance & Damage category & Damage unit \\
\hline 769 [a] & $\begin{array}{l}\text { Human toxicity } \\
\text { (carcinogens + non-carcinogens) }\end{array}$ & $\mathrm{kg}_{\mathrm{eq}}$ chloroethylene into air & Human health & \multirow[t]{5}{*}{ DALY } \\
\hline 12 [b] & Respiratory (inorganics) & $\mathrm{kg}_{\text {eq }}$ PM2.5 into air & Human health & \\
\hline 25 [b] & lonizing radiations & $\mathrm{Bq}$ eq carbon-14 into air & Human health & \\
\hline $22[\mathrm{~b}]$ & Ozone layer depletion & $\mathrm{kg}_{\mathrm{eq}}$ CFC-11 into air & Human health & \\
\hline \multirow[t]{2}{*}{$130[\mathrm{~b}]$} & \multirow{2}{*}{$\begin{array}{l}\text { Photochemical oxidation } \\
\text { [= Respiratory (organics) for human health] }\end{array}$} & \multirow[t]{2}{*}{$\mathrm{Kg}_{\text {eq }}$ ethylene into air } & Human health & \\
\hline & & & Ecosystem quality & - \\
\hline $393[\mathrm{a}]$ & Aquatic ecotoxicity & $\mathrm{kg}_{\mathrm{eq}}$ triethylene glycol into water & Ecosystem quality & \multirow[t]{3}{*}{$\mathrm{PDF}^{*} \mathrm{~m}^{2 *} \mathrm{yr}$} \\
\hline $393[\mathrm{a}]$ & Terrestrial ecotoxicity & $\mathrm{kg}_{\mathrm{eq}}$ triethylene glycol into water & Ecosystem quality & \\
\hline $5[\mathrm{~b}]$ & Terrestrial acidification/nutrification & $\mathrm{kg}_{\mathrm{eq}} \mathrm{SO}_{2}$ into air & Ecosystem quality & \\
\hline $10[c]$ & Aquatic acidification & $\mathrm{kg}_{\mathrm{eq}} \mathrm{SO}_{2}$ into air & Ecosystem quality & $\begin{array}{c}\text { Under } \\
\text { development }\end{array}$ \\
\hline $10[c]$ & Aquatic eutrophication & $\mathrm{kg}_{\mathrm{eq}} \mathrm{PO}_{4}{ }^{3-}$ into water & Ecosystem quality & $\begin{array}{c}\text { Under } \\
\text { development }\end{array}$ \\
\hline $15[b]$ & Land occupation & $\mathrm{m}^{2}{ }_{e q}$ organic arable land year & Ecosystem quality & PDF ${ }^{*} m^{2 *} y r$ \\
\hline $38[b]$ & Global warming & $\mathrm{kg}_{\mathrm{eq}} \mathrm{CO}_{2}$ into air & $\begin{array}{l}\text { Climate change } \\
\text { (life support system) }\end{array}$ & $\left(\mathrm{kg}_{\mathrm{eq}} \mathrm{CO}_{2}\right.$ into air) \\
\hline 9 [d] & Non-renewable energy & $\begin{array}{l}\text { MJ Total primary non-renewable } \\
\text { or } \mathrm{kg}_{\mathrm{eq}} \text { crude oil }\left(860 \mathrm{~kg} / \mathrm{m}^{3}\right)\end{array}$ & Resources & \multirow[t]{2}{*}{ MJ } \\
\hline $20[b]$ & Mineral extraction & $\begin{array}{l}\text { MJ additional energy } \\
\text { or } \mathrm{kg}_{\mathrm{eq}} \text { iron (in ore) }\end{array}$ & Resources & \\
\hline
\end{tabular}




\subsection{Human toxicity (carcinogens and non-carcinogens)}

Characterization factors for chronic toxicological effects on human health, termed Human Toxicity Potentials (HTP) at midpoint- and Human Damage Factors (HDF) at damage level, provide estimates of the cumulative toxicological risk and potential impacts associated with a specified mass $(\mathrm{kg})$ of a chemical emitted into the environment. These are determined with the tool IMPACT 2002 (Impact Assessment of Chemical Toxics $)^{1}$, which models risks and potential impacts per emission for several thousand chemicals (Pennington et al. 2003a, 2003b). Generic factors are calculated at a continental level for Western Europe, whereas spatial differentiation for 50 watersheds and air cells in Europe is also enabled.

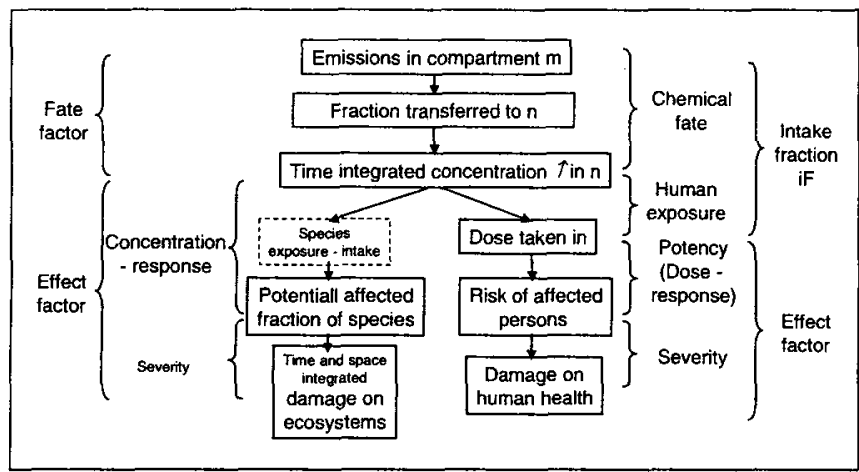

Fig. 2: General scheme of the Impact pathway for human toxicity and ecotoxicity (Jolliet et al. 2003b)

Fig. 2 summarizes the different types of relevant information regarding human toxicity: fate, which is composed of transport in the environment, exposure, and the resulting intake. This is then combined with an effect factor characterizing the potential risks linked to the toxic intakes. Severity finally characterizes the relative magnitude of the damage due to certain illnesses. The Human Damage Factor of substance i $\left(\mathrm{HDF}_{\mathrm{i}}\right.$, in DALY (Disability Adjusted Life Years) per $\mathrm{kg}_{\text {emitred }}$ is calculated as follows:

$\mathrm{HDF}_{\mathrm{i}}=\mathrm{iF}_{\mathrm{I}} \cdot \mathrm{EF}_{\mathrm{i}}=\mathrm{iF_{1 }} \cdot \beta_{\mathrm{i}} \cdot \mathrm{D}_{\mathrm{i}}$

The intake fraction (iF) is the fraction of mass of a chemical released into the environment that is ultimately taken in by the human population as a result of food contamination, inhalation, or dermal exposure (Bennet et al. 2002a, 2002b), in $\mathrm{kg}_{\text {intake }}$ per $\mathrm{kg}_{\text {emitted }}$. The effect factor $(\mathrm{EF})$ is the product of the dose-response slope factor $(\beta$, in risk of incidence per $\left.\mathrm{kg}_{\text {intake }}\right)$ and of the severity ( $\mathrm{D}$, in DALY per incidence).

The intake fraction, therefore, accounts for a chemical's fate in regards to multimedia and spatial transport as well as human exposure associated with food production, water supply, and inhalation. The complete fate and exposure assessment enables the estimation of a chemical's mass (or

\footnotetext{
1 'IMPACT 2002' denotes the model which focuses on human toxicity and ecotoxicity, while the complete LCIA methodology, with all impact categories, is termed 'IMPACT 2002+'
}

concentration) in the environmental media at a regional or at a global scale using the same basic model. Per default, characterization factors are calculated for emissions into a Western European system nested in a global box. Special attention was paid to air modeling and a new simple and accurate method has been developed to account for the intermittent character of rainfall in a steady-state model. The IMPACT 2002 model accounts for multiple exposure pathways that link a chemical's concentration in the atmosphere, soil, surface water, or in vegetation to human uptake through inhalation and ingestion. Ingestion pathways include drinking water consumption, incidental soil ingestion, and intake of contaminants from agricultural products (fruits, vegetables, grains, etc.), as well as from animal products, such as beef-, pork-, and poultry-meat, eggs, fish, and milk. Compared to conventional approaches, the transfer of contaminants into the human food is no more based on consumption surveys, but accounts for agricultural and livestock production levels that are eventually eaten by humans, independently from their living location. Latest developments also include the calculation of pesticide residues in food due to direct applications. The intake fraction concept also facilitates the comparison between indoor and outdoor emissions, with the intake fraction for indoor air emissions being a direct function of the ventilation rate per inhabitant.

For the effect factor, IMPACT 2002 uses a new approach to calculate the health effect metric for non-cancer toxicological impacts. The selected measure is the $\mathrm{ED}_{10}$, the effect dose inducing a $10 \%$ response over background. It is derived from the health-risk-assessment concept of benchmark dose to estimate a default linear low-dose extrapolation, as detailed by Crettaz et al. (2002) for cancer effects and by Pennington et al. (2002) for non-cancer effects. One gets:

$\beta_{\text {human }}=\frac{0.1}{\mathrm{ED}_{10}} \cdot \frac{1 \cdot}{\mathrm{BW} \cdot \mathrm{LT}_{\mathrm{h}} \cdot \mathrm{N}_{365}}$

with:

$\beta_{\text {human }}$ Human health effect factor [risk of an incidence per $\mathrm{kg}$ cumulative intake]

$E D_{10}$ Benchmark dose resulting in $10 \%$ effect over background [mg/ $\mathrm{kg} /$ day]

BW Average body weight in considered population [kg/pers]

$L T_{h} \quad$ Average lifetime of humans in considered population in years [yr]

$\mathrm{N}_{365} \quad$ Number of days per year [days/yr]

Preliminary $\beta$ slope factors were calculated from bioassays on animal data using best-estimate extrapolation factors from TD50, NO(A)EL, and LO(A)EL data ${ }^{2}$. The DALY (Disability Adjusted Life Years (Murray and Lopez 1996)) characterizes severity, accounting for both mortality (Years of Life Lost (YLL) due to premature death) and morbidity. Default DALY values of 6.7 and 0.67 [years/incidence] are adopted for most carcinogenic and non-carcinogenic effects, respectively.

2 Toxic Dose 50\%, No and Low Observed (Adverse) Effect Levels 
There is no real midpoint for human toxicity as intermediary parameters for fate and exposure like intake fraction (see above) cannot be interpreted on their own. A real midpoint could be the number of cases for the same illness. However, as one or several substances cause a large number of illnesses, risk of illnesses cannot be added up without considering implicitly (equal severity), or preferably explicitly, their respective severity. The characterization factors at midpoint are therefore simply obtained by dividing the $\mathrm{Hu}$ man Damage Factor of the considered substance by that of the reference substance, which is chloroethylene (declared human carcinogen with well defined fate data and a main impact pathway by air inhalation):

$\mathrm{HTP}_{\mathrm{i}}=\mathrm{HDF}_{\mathrm{i}} / \mathrm{HDF}_{\text {chloroethylene }}$,

in $\mathrm{kg}_{\text {eq }}$ chloroethylene into air per $\mathrm{kg}_{\mathrm{i}}$

Expressing scores in kg-equivalent of a reference substance facilitates communication and stresses that these characterization factors are mostly interesting for relative comparisons rather than for their absolute values.

\subsection{Aquatic and terrestrial ecotoxicity}

In many respects, impacts on aquatic ecosystems are treated similar to human toxicity including both fate and effect, with however some noticeable differences. First, one is generally interested in effect at species level rather than on individuals. Second, the same fate model is applied as for human toxicity, but the interface between fate and effect is at the level of concentration (see Fig. 2). Fate enables to relate emissions to the change in concentration in the pure aqueous phase of freshwater. Exposure is generally implicitly taken into account in the effect factor that characterizes the risks at species level, eventually leading to a Potentially Affected Fraction (PAF) or Potentially Disappeared Fraction (PDF) of species and to a preliminary indicator of damages on ecosystems.

For aquatic freshwater ecosystems, the time- and space-integrated Potentially Affected Fraction of species per unit of emission (APAF, in PAF. $\mathrm{m}^{3} \cdot \mathrm{year} / \mathrm{kg}$ ) is therefore estimated on the basis of a fate factor ( $F \cdot \theta$, in years) and an effect factor $\left(\beta\right.$, in PAF $\left.\mathrm{m}^{3} / \mathrm{kg}\right)$ as follows:

$$
\operatorname{APAF}_{\mathrm{i}}=\mathrm{F}_{\mathrm{i}}^{\mathrm{mw}} \cdot \theta_{\mathrm{i}}^{\mathrm{w}} \cdot \beta_{\mathrm{i}}, \text { in PAF } \cdot \mathrm{m}^{3} \cdot \text { year } / \mathrm{kg}
$$

The fate factor itself is obtained by the multiplication of two parameters that are calculated using the IMPACT 2002 model (Pennington et al. 2003a): $\mathrm{F}_{\mathrm{i}}^{\mathrm{mw}}$ is the dimensionless fraction of the emission of substance $i$ in compartment $m$ transferred to freshwater. $\theta_{i}^{\mathrm{w}}$, in years, is the equivalent residence time of substance $i$ in water, equal to the inverse of the overall decay rate constant in water $(k)$. It also corresponds to the time- and space-integrated increase in concentration in the aquatic freshwater per mass input of chemical $M$ released into the aquatic environment:

$\theta=1 / \mathrm{k}=\Delta \mathrm{C} \cdot \mathrm{V} \cdot \Delta \mathrm{t} / \mathrm{M}$
$\Delta \mathrm{C}$ (in $\left.\mathrm{kg} / \mathrm{m}^{3}\right)$ is the concentration increase in the volume of water $\mathrm{V}$ (in $\mathrm{m}^{3}$ ), due to an emission flow of $\mathrm{M} \Delta \mathrm{t}$ (in $\mathrm{kg}$ / year). This space integration differs from traditional regulatory-orientated risk assessment based on pure PEC/PNEC approaches (predicted concentration divided by predicted no effect concentration). Introducing the volume of water that is polluted to a certain level accounts for the fact that polluting all the lakes in Europe versus a small lake is not equivalent in term of impacts. The aquatic ecotoxicological characterization factors do not include an exposure component to account for bio-magnification (additional exposure due to contaminants in food, including suspended particulate matter). Only bio-concentration is considered (direct transfer of chemicals from the exposure medium to the species, as observed in aquatic laboratory toxicity tests).

The risk-based effect factor $\left(\beta_{\mathrm{i}}\right)$ is the change in the Potentially Affected Fraction of species that experiences an increase in stress for a change in contaminant concentration. As described in the AMI method for aquatic ecosystems (Payet et al. 2003), the effect factor assesses the mean impact on species, using the $\mathrm{HC} 50$, the mean hazardous concentration affecting $50 \%$ of the species present in the ecosystem:

$\beta_{\mathrm{i}}=0.5 / \mathrm{HC}_{0} 0_{i}^{\mathrm{w}}$ (in $\mathrm{PAF} \mathrm{m} \mathrm{m}^{3} / \mathrm{kg}$ )

This $\mathrm{HC} 50$, in $\mathrm{kg} / \mathrm{m}^{3}$, is itself calculated as the geometric mean of available EC50s ${ }^{3}$ on individual species. For comparative assessments it is better suited than regulatory PNEC approaches based on most sensitive species, since the latter are too sensitive to the species eventually tested.

At midpoint level, the freshwater Aquatic Ecotoxicity Potential $\left(\mathrm{AEP}_{\mathrm{i}}\right.$ in $\mathrm{kg}_{\mathrm{eq}}$ triethylene glycol into water per $\left.\mathrm{kg}_{\mathrm{i}}\right)$ is derived by normalization to the reference substance, triethylene glycol:

$\mathrm{AEP}_{\mathrm{i}}=\frac{\mathrm{APAF}_{\mathrm{i}}}{\mathrm{APAF}_{\text {triethylene glycol }}}$

Terrestrial ecotoxicity potentials are calculated in a similar way. As data availability is limited, terrestrial $\mathrm{HC} 50$ s are mostly extrapolated from aquatic $\mathrm{HC} 50^{\mathrm{w}}$ with the method proposed by Hauschild and Wenzel (1998), as a function of the adsorption coefficient of the considered substance $i\left(\mathrm{~K}_{\mathrm{di}}\right.$, in $\mathrm{m}^{3} / \mathrm{kg}$ ), the soil density $\left(\rho^{\mathrm{s}}\right.$, in $\left.\mathrm{kg} / \mathrm{m}^{3}\right)$, and the dimensionless volumetric water content of soil $\left(\mathrm{f}^{\mathrm{w}}\right)$ :

$\mathrm{HC} 0_{\mathrm{i}}^{\mathrm{s}}=\mathrm{HC} 50_{\mathrm{i}}^{\mathrm{w}}\left(\mathrm{K}_{\mathrm{di}} \mathrm{P}^{\mathrm{s}}+\mathrm{f}^{\mathrm{w}}\right)$

\subsection{Other midpoint category effects}

The characterization factors for the midpoint categories respiratory effects, photochemical oxidation, ionizing radiation, ozone layer depletion, terrestrial acidification/nutrification, land use occupation, and mineral extraction are obtained from

${ }^{3}$ Effect concentration, where $50 \%$ of the population of a species are affected 
Eco-indicator 99 (Goedkoop and Spriensma 2000), adopting the default egalitarian scenario and by normalization to a reference substance. For climate change, the latest IPCC Global Warming Potentials (IPCC 2001) have been used with a 500 years time horizon to account for long term effects.

The characterization factors for aquatic acidification and aquatic eutrophication are adapted from Hauschild and Wenzel (1998), which also correspond to Guinée et al. (2002). Aquatic eutrophication is divided into two classes, respectively valid for $\mathrm{P}$-limited and $\mathrm{N}$-limited watersheds. The values for P-limited watersheds are applied by default as recent evidence shows that ultimately phosphorus is the relevant compound in most cases. This can be explained by the fact that cyano-bacteria in lakes and rivers are fixing the atmospheric $\mathrm{N}$ when nitrates are limiting in the aquatic media. Therefore, in the long term, increases in nitrate concentration will not influence the ecosystem's development, whilst an increase in phosphate will always lead to an increasing impact, except in particular areas as for example estuarial ecosystems (Barroin 2003).

Characterization factors for non-renewable energy consumption, in terms of the total primary energy extracted, are calculated with the upper heating value (Frischknecht et al. 2003).

\section{Damage Categories}

Damage characterization factors of any substance can be obtained by multiplying the midpoint characterization potentials with the damage characterization factors of the reference substances (Table 2). The present Section shortly details how these damage characterization factors were determined.

Human Health. Human toxicity (carcinogenic and non-carcinogenic effects), respiratory effects (inorganics and organics), ionizing radiation, and ozone layer depletion all contribute to human health damages. As for human toxicity (see Eq. 3), all of these midpoint characterization factors can be expressed straightforwardly in $\left[\mathrm{DALY} / \mathrm{kg}_{\text {emission }}\right]^{4}$.

${ }^{4} \mathrm{Or}\left[/ \mathrm{Bq}_{\text {emission }}\right]$ for the 'ionizing radiation' midpoint category
Ecosystem Quality. The midpoint categories terrestrial acidification, terrestrial nutrification, and land occupation were directly taken from Eco-indicator 99 and their impact can directly be determined as a Potentially Disappeared Fraction over a certain area and during a certain time per $\mathrm{kg}$ of emitted substance, expressed in [PDF. $\mathrm{m}^{2} \cdot$ year $\left./ \mathrm{kg}_{\text {emitted }}\right]$. For ecotoxicity, the midpoint assessment is based on the timeand volume-integrated Potentially Affected Fraction of species, expressed in terms of [PAF. $\mathrm{m}^{3} \cdot$ year $/ \mathrm{kg}$ ] (see Eq. 4). Four different approaches are possible to convert PAF into PDF: (1) Eco-indicator 99 (Goedkoop and Spriensma 2000), which uses a direct extrapolation factor of ten between the NOEC based PAF and PDF; (2) The second family of models focuses on the recovery potential of species exposed to chemicals; (3) Tools based on an assessment of the probability of the extinction of species under toxicant stress, which are currently used in conservation biology; (4) An assessment of change in genetic diversity. After a comparison of all these options (Payet 2002), the simple extrapolation factor has been employed for Impact 2002+. The variability among the different methods was less than one order of magnitude and the alternative methods cannot be easily applied in LCIA approaches, since they are not compatible with the assumption of time and space integration of impacts. For Impact $2002+$, though, the factor has to be changed compared to Eco-indicator 99, as the HC50 is based on EC50 instead of NOEC, yielding a factor 0.5 . This represents the assumption that one half of the species affected over their level of chronic EC50 will disappear due to the toxic stress, resulting in the following Aquatic Ecotoxicity Damage Factor (AEDF, in [PDF $\mathrm{m}^{2} \cdot$ year $\left./ \mathrm{kg}_{\text {emitted }}\right]$ ) for a substance i:

$\mathrm{AEDF}_{\mathrm{i}}=0.5 \cdot \mathrm{APAF}_{\mathrm{i}} / \mathrm{h}^{\mathrm{w}}$, where $h^{w}$ is the mean depth of freshwater, in [m]

Extrapolation methods are presently under development for damage factors characterizing impacts on ecosystem quality caused by aquatic acidification and aquatic eutrophication. In addition, photochemical oxidation and ozone depletion also potentially contribute to the overall impacts on

Table 2: Characterization damage factors of the various reference substances

\begin{tabular}{|c|c|c|}
\hline Midpoint categories & Damage factors & Units \\
\hline Carcinogens & 1.45E-06 & DALY/kg chloroethylene \\
\hline Non-carcinogens & $1.45 E-06$ & DALY/kg chloroethylene \\
\hline Respiratory inorganics & 7.00E-04 & DALY/kg PM2.5 \\
\hline Ozone layer & $1.05 E-03$ & DALY/kg CFC-11 \\
\hline Radiation & $2.10 \mathrm{E}-10$ & DALY/Bq carbon-14 \\
\hline Respiratory organics & $2.13 E-06$ & DALY/kg ethylene \\
\hline Aquatic ecotoxicity & 8.86E-05 & PDF. $\mathrm{m}^{2} \cdot \mathrm{yr} / \mathrm{kg} \cdot$ triethylene glycol \\
\hline Terrestrial ecotoxicity & $8.86 E-05$ & $\mathrm{PDF} \cdot \mathrm{m}^{2} \cdot \mathrm{yr} / \mathrm{kg} \cdot$ triethylene glycol \\
\hline Terrestrial acidification/nutr. & 1.04 & $\mathrm{PDF} \cdot \mathrm{m}^{2} \cdot \mathrm{yr} / \mathrm{kg} \mathrm{SO}{ }_{2}$ \\
\hline Land occupation & 1.09 & $\mathrm{PDF} \cdot \mathrm{m}^{2} \cdot \mathrm{yr} / \mathrm{m}^{2}$.organic arable land $\cdot \mathrm{yr}$ \\
\hline Global Warming & 1 & $\mathrm{~kg} \mathrm{CO} / 2 \mathrm{~kg} \mathrm{CO} 2$ \\
\hline Mineral extraction & $5.10 \mathrm{E}-02$ & $\mathrm{MJ} / \mathrm{kg}$ iron \\
\hline Non-renewable energy & 45.6 & MJ/kg crude oil \\
\hline
\end{tabular}


ecosystems. However, lack of adequate scientific information does not allow, at the moment, to quantify their single contributions in term of Potentially Disappeared Fraction. If desired, these effects could be considered by including these midpoints categories in the weighting phase (see below).

Climate Change. From the authors' point of view, thus far the modeling up to the damage of the impact of climate change on ecosystem quality and human health is not accurate enough to derive reliable damage characterization factors. The interpretation, therefore, directly takes place at midpoint level, which can be interpreted as damage on life support systems that deserve protection for their own sake. The global warming is considered as a stand-alone endpoint category with units of $\left[\mathrm{kg}_{\mathrm{eq}} \mathrm{CO}_{2}\right]$, which is normalized in the next step. The assumed time horizon is also 500 years to account for both shortterm and long-term effects as there is little evidence that global warming effects will decrease in the future.

Resources. The two midpoint categories contributing to the endpoint category 'resources' are mineral extraction and nonrenewable energy consumption. Damages due to mineral resource extraction are specified according to Eco-indicator 99, with the concept of surplus energy (in [MJ]). This is based on the assumption that a certain extraction leads to an additional energy requirement for further mining of this resource in the future, caused by lower resource concentrations or other unfavorable characteristics of the remaining reserves (Goedkoop and Spriensma 2000).

Whereas minerals could still be potentially accessible for further use, even after waste disposal, dissipated non-renewable energy is not any more available at a functional exergy level. If an infinite time horizon is considered, this implies that the total energy content is lost as a resource, in addition to the surplus energy. Therefore, contrary to Eco-indicator 99, the overall non-renewable primary energy is assessed for non-renewable energy resources, including feedstock energy for energy carriers (upper heating values). The endpoint unit of impacts on resources is the amount of additional primary energy required per unit of mineral and of total non-renewable primary energy for energy carriers, in $\left[\mathrm{MJ} /\right.$ unit $\left._{\text {consumed }}\right]$.

\section{Normalization and Weighting}

The idea of normalization is to analyze the respective share of each impact to the overall damage by applying normalization factors to midpoint- or damage impact classes in order to facilitate interpretation. The normalized factor is determined by the ratio of the impact per unit of emission divided by the total impact of all substances of the specific category for which characterization factors exist, per person per year. The unit of all normalized midpoint/damage factors is therefore [pers-year/unit ${ }_{\text {emission }}{ }^{5}$, i.e. the number of equivalent persons affected during one year per unit of emission. An alternative would be to normalize to $\mathrm{m}^{2}$-years equivalents, as in the Critical Surface-Time 95 LCIA method (Jolliet 1994, Jolliet and Crettaz 1997), the predecessor of

${ }^{5}$ The units can be expressed per $\left[\mathrm{kg}_{\text {emitred }}\right]$, per $\left[\mathrm{Bq}_{\mathrm{eminted}}\right]$, or per [ $\mathrm{m}^{2}$.year]
Table 3: Normalization factors for the four damage categories for Western Europe

\begin{tabular}{l|c|l}
\hline Damage categories & $\begin{array}{c}\text { Normalization } \\
\text { factors }\end{array}$ & Unit \\
\hline Human health & 0.0077 & $\mathrm{DALY} / \mathrm{pers} / \mathrm{yr}$ \\
\hline Ecosystem Quality & 4650 & $\mathrm{PDF} \cdot \mathrm{m}^{2} \cdot \mathrm{yr} / \mathrm{pers} / \mathrm{yr}$ \\
\hline Climate Change & 9950 & $\mathrm{~kg} \mathrm{CO} / \mathrm{pers} / \mathrm{yr}$ \\
\hline Resources & 152000 & $\mathrm{MJ} / \mathrm{pers} / \mathrm{yr}$ \\
\hline
\end{tabular}

IMPACT 2002+. In priority, the authors suggest to perform normalization after the damage characterization. For those who would like to stop at midpoint level, appropriate normalization factors are also available. An overview of normalization factors for the four damage categories is given in Table 3.

Human Health. The normalization factor is calculated according to Eco-indicator 99, with two modifications: impacts on human health caused by climate change are not taken into account (see above) and human toxicity is calculated as the sum of carcinogenic and non-carcinogenic effects. For each pollutant, the impact in [DALYs $/ \mathrm{kg}_{\text {emitred }}$ ] is multiplied with the annual emissions in Western Europe (per media: air, soil and water). This gives the overall DALYs annually lost by this specific pollutant in Europe. The total human health impacts per year is obtained by summing up the results for all pollutants, i.e. 2.92.106 [DALY/year]. Finally, this value is divided by the European population $\left(380 \cdot 10^{6}\right)$ to obtain the adopted human health normalization factor of 7.7.10-3 [DALYs/pers/year], expressing a reduction of life expectancy of about three days per year and per person.

Ecosystems Quality. This normalization factor is determined similarly to Eco-indicator 99, with two modifications: the damage to ecosystem quality caused by land conversion and photochemical oxidation have not been taken into account and the damage to ecosystem quality caused by ecotoxicological emissions has been broken down into damages to aquatic ecosystems and terrestrial ecosystems.

Climate Change. The normalization factor for climate change is based on the total gaseous emissions released in Europe per year multiplied with the global warming potentials for a 500 years horizon. The total global warming score related to Western European emissions is $3.78 \cdot 10^{12}\left[\mathrm{~kg}_{\mathrm{eq}} \mathrm{CO}_{2} /\right.$ year $]$. This value has been divided by the Western European population (380.106 inhabitants) to obtain the amount of global warming gases emitted per person and per year, which is $9.95 \cdot 10^{3}\left[\mathrm{~kg}_{\mathrm{eq}} \mathrm{CO}_{2} /\right.$ pers/year $]$.

Resources. The normalization factor for resources is calculated with the total non-renewable energy consumption in Western Europe, including nuclear energy consumption.

Weighting. The authors suggest considering the four-damage oriented impact categories human health, ecosystem quality, climate change, and resources separately for the interpretation phase of LCA. However, if aggregation is needed, one could use self-determined weighting factors or a default weighting factor of one, unless other social weighting values are available. 


\section{Conclusions and Outlook}

The IMPACT 2002+ LCIA methodology proposes an attractive implementation of a combined midpoint/damage approach, with new developments in the comparative assessment of human toxicity and ecotoxicity. Several limitations must however be mentioned: several impact categories have not been considered that far, such as impacts on the marine environment, noise, etc. For the ecotoxicity and human toxicity of metals, further research is presently under way, aiming at the consideration of speciation and bioavailability. Efforts are also carried out to extend the assessment to a much wider number of considered LCI-results, aided by newly available databases.

Acknowledgments. The authors would like to thank all researchers who have very significantly contributed to the development of the scientific basis supporting the IMPACT 2002+ model, especially David Pennington, Christophe Amman and Pierre Crettaz. We would also like to thank the Swiss EPA (BUWAL) and the French EPA (ADEME), who funded some of the research leading to IMPACT $2002+$.

\section{References}

Barroin G (2003): Phosphore, Azote et Prolifération des Végétaux Aquatiques. Courrier de l'Environnement de l'INRA; no. 48, 13-25

Bennett DH, Margni M, McKone TE, Jolliet O (2002b): Intake Fraction for Multimedia Pollutants: A Tool for Life Cycle Analysis and Comparative Risk Assessment. Risk Analysis 22, 903-916

Bennett DH, McKone TE, Evans JS, Nazaroff WW, Margni MD, Jolliet O, Smith KR (2002a): Defining Intake Fraction. Environ Sci Technol 36, 207A-211A

BUWAL (1999): Ökologische Bewertung mit Hilfe der Grauen Energie. Schriftenreihe Umwelt, Ökobilanzen, Vol. 307, Bern (CH)

Crettaz P, Pennington D, Rhomberg L, Brand B, Jolliet O (2002): Assessing Human Health Response in Life Cycle Assessment Using ED10s and DALYs: Part 1-Cancer Effects. Risk Analysis 22, 931-946

Frischknecht et al. (2003): ecoinvent Database, http://www.ecoinvent.ch/ Goedkoop M, Spriensma R (2000): The Eco-indicator 99: A Damage Oriented Method for Life Cycle Assessment, Methodology Report, second edition. Pré Consultants, Amersfoort (NL), Netherlands

Guinée JB, Gorrée M, Heijungs R, Huppes G, Kleijn R, van Oers L, Wegener Sleeswijk A, Suh S, Udo de Haes HA, de Bruijn $\mathrm{H}$, van Duin R, Huijbregts MAJ (2002): Life Cycle Assessment: An Operational Guide to the ISO Standards. Kluwer Academic Publishers, Dordrecht (NL)

Hauschild M, Wenzel H (1998): Environmental Assessment of Products - Vol. 2: Scientific Background, Chapman \& Hall, London(UK)
Heijungs R, Guinée JB, Huppes G, Lankreijer RM, Udo de Haes HA, Wegener Sleeswijk A, Ansems AMM, Eggels PG, van Duin R, Goede HP (1992): Environmental Life Cycle Assessment of Products. Centre of Environmental Science (CML), Leiden (NL)

IPCC (2001): Climate change 2001: The Scientific Basis. Intergovernmental Panel on Climate Change (IPCC), http://www.grida.no/ climate/ipce tar/, 385-391

Jolliet O (1994): Critical Surface-Time: An Evaluation Method for Life Cycle Assessment. In: Udo de Haes HA et al. (Ed.): Integrating Impact Assessment into LCA. SETAC Press, 133-142

Jolliet O, Brent A, Goedkoop M, Itsubo N, Mueller-Wenk R, Peña C, Schenk R, Stewart M, Weidema B (2003a): LCIA Definition Study of the SETAC-UNEP Life Cycle Initiative. UNEP, http:// www.uneptie.org/pc/sustain/lcinitiative/

Jolliet O, Crettaz P (1997): Critical Surface-Time 95, a Life Cycle Impact Assessment Methodology, including Exposure and Fate, EPFL (CH)

Jolliet O, Pennington D, Amman C, Pelichet T, Margni M, Crettaz P (2003b): Comparative Assessment of the Toxic Impact of Metals on Humans within IMPACT 2002. In: Dubreuil A (Ed.): Life Cycle Assessment of Metals - Issues and Research Directions, SETAC Press, ISBN 1-880611-62-7

Murray C, Lopez A (1996): The Global Burden of Disease, a Comprehensive Assessment of Mortality and Disability from Diseases, Injuries, and Risk Factors in 1990 and Projected to 2020. Global Burden of Disease and Injury Series, Vol.1 \& 2; Harvard School of Public Health, World Health Organization and World Bank

Payet J (2002): Developpement de la Méthode AMI. ADEME Report, Agence de l'Environnement et de la Maîtrise de l'Energie; Paris ( $F$ )

Payet J, Jolliet $O$ (2003): Comparative Assessment of the Toxic Impact of Metals on Aquatic Ecosystems: the AMI Method. In: Dubreuil A (Ed.): Life Cycle Assessment of Metals - Issues and Research Directions, SETAC Press, ISBN 1-880611-62-7

Payet J, Pennington D, Hauschild M., Jolliet O (2003): Comparative Assessment of Toxic Impacts on Aquatic Ecosystems: The AMI method (Assessment of the Mean Impact). Submitted to Environ Toxicol Chem

Pennington D, Amman C, Pelichet T, Margni M, Jolliet O (2003b): Spatial Multimedia Chemical Fate and Human Exposure Model for Western Europe. Submitted to Environ Sci Technol

Pennington D, Crettaz P, Tauxe A, Rhomberg L, Brand B, Jolliet O (2002): Assessing Human Health Response in Life Cycle Assessment Using ED10s and DALYs: Part 2-Noncancer Effects. Risk Analysis 22, 947-963

Pennington D, Margni M, Payet J, Charles R, Jolliet O (2003a): Estimating Cumulative Toxicological Risks and Potential Impacts for Human Health and Ecosystems in LCA. Submitted to Environ Toxicol Chem

Steen B (1999): A systematic Approach to Environmental Priority Strategies in Product Development (EPS). 2000-General System Characteristics \& 2000-Models and Data. Chalmers, CPM report: 1999, 4 and 5, http://eps.esa.chalmers.se/download.htm
Olivier Jolliet is assistant professor at the Swiss Federal Institute of Technology Lausanne (EPFL), Switzerland, heading the Industrial Ecology \& Life Cycle Systems Group. His research focuses on preventing and reducing emissions and resource consumption by modeling life cycle systems, with an emphasis on innovative technologies (telecommunication \& information systems, environmentally friendly biomaterials, waste treatment technologies \& recycling). A second focus is the modeling of multicompartment systems for fate \& exposure to assess the life cycle impacts of toxics on human health and ecosystems, in collaboration with the chemical and automotive industries.

Olivier Jolliet is the scientific responsible and manager of the Life Cycle Impact Assessment programme of the UNEP (United Nations Environment Program) / SETAC Life Cycle Initiative.
$\mathrm{He}$ is editor and/or reviewer for several scientific journals (Environmental Toxicity and Chemistry, Chemosphere, Int J LCA, Journal of Industrial Ecology, Journal of Cleaner Production). Olivier Jolliet obtained a Master, and a Ph.D. in physics in 1988. He worked as a postdoc at the Silsoe Research Institute (GB) and as a visiting scholar at MIT (USA).

Prof. Olivier Jolliet, Ecole Polytechnique Fédérale de Lausanne (EPFL), Industrial Ecology - Life Cycle Systems Group, EPFLENAC-GECOS, CH-1015 Lausanne, Switzerland; T: +41-21-6935775; F: +41-21-693-5760; olivier.jolliet @ epfl.ch; http://gecos.epfl. ch/lcsystems/ 